\title{
Effects of magnetic field and rare earth addition on corrosion behavior of
}

\author{
Al-3.0 wt.\% Mg alloy \\ Xin Zhang ${ }^{1}$, Zehua Wang ${ }^{1, *}$, Zehua Zhou ${ }^{1}$ and Jianming $\mathrm{Xu}^{2}$ \\ ${ }^{1}$ College of Mechanics and Materials, Hohai University, Nanjing 210098, China; \\ ${ }^{2}$ Zhangjiagang Hongji Aluminum Co. Ltd., 18 Dosan Road, Suzhou 215600, China.
}

\begin{abstract}
Effect of magnetic field and rare earth on the corrosion behavior of Al-3.0 wt.\%Mg alloy in 3.5 wt.\% $\mathrm{NaCl}$ solution was investigated by immersion test and electrochemical measurement. The results indicated that a horizontal magnetic field would increase the corrosion potential $\left(\mathrm{E}_{\mathrm{corr}}\right)$, impede the growth of pitting holes and reduce the corrosion current density $\mathrm{i}_{\text {corr }}$ and corrosion rate of Al-3.0 wt. $\% \mathrm{Mg}-\mathrm{xR} \mathrm{R}_{\mathrm{E}}$ alloys. Proper content of $\mathrm{R}_{\mathrm{E}}$ would increase the corrosion resistance of Al-3.0 wt. $\% \mathrm{Mg}$ alloys. Excessive $\mathrm{R}_{\mathrm{E}}$ would enhance the effect of magnetic field on the pitting corrosion sensibility and increased the corrosion rate of Al-3.0 wt.\% Mg alloys due to the increase of the number and the size of the second phases.
\end{abstract}

Key words: Al-3.0wt.\%Mg alloy, rare earth elements, applied magnetic field, pitting corrosion.

\section{Introduction}

On some special occasions, $\mathrm{Al}$ alloy can be used as substitutes for some rare metallic materials and is considered as the electromagnetic shielding materials due to their excellent comprehensive properties[1-5]. Because of their excellent corrosion resistance, Al-Mg alloys can be specified outdoor applications. Nevertheless, these alloys still have corrosion problems. For example, it is well known that Al-Mg alloys, especially those with high content of $\mathrm{Mg}$, are susceptible to pitting corrosion[6-8]. So many kinds of technologies have been developed to reduce the pitting corrosion problem[9-18]. Al-Mg electromagnetic shielding wire is served in magnetic field, however, the influence of this special environment on its corrosion behavior is not clear and the method to increase the corrosion resistance of this alloy is lack of research.

In order to improve the corrosion resistance of Al-Mg alloys, many attentions have been paid to the alloying technology[17-18]. In our previous work, mischmetal (37.3 wt.\%La, 61.5 wt.\%Ce) has been used to improve the

\footnotetext{
${ }^{1}$ Corresponding authors at: Institute of Metals and Protection, College of Mechanics and Materials, Hohai University, 1 Xikang Road, Nanjing 210098, Jiangsu Province, PR China.

Tel./fax: +862583787681.

E-mail address: zhwang@hhu.edu.cn(Z.Wang), zhangxin.007@163.com(X. Zhang).
} 
corrosion resistance of Al-3.0 wt.\% Mg alloy[19] and the corrosion behavior of Al-3.0 wt.\% Mg alloy under applied magnetic field has also been studied[20]. It indicated that $0.4 \mathrm{~T}$ horizontal magnetic field would increase the pitting corrosion potential $\left(\mathrm{E}_{\mathrm{pit}}\right)$, decrease the corrosion current density $\left(\mathrm{i}_{\mathrm{corr}}\right)$, prolong the pit initiation time, slow down the pit generation rate and inhibit the growth of pitting of the tested alloys in $3.5 \mathrm{wt} \% \mathrm{NaCl}$ solution. However, the effect of magnetic field on the corrosion behavior of Al-3.0 wt. $\% \mathrm{Mg}-\mathrm{x} \mathrm{R}_{\mathrm{E}}$ has not been studied systematically. In this paper, the effect of magnetic field on the corrosion behavior of $\mathrm{Al}-3.0 \mathrm{wt} . \% \mathrm{Mg}-\mathrm{x} \mathrm{R}_{\mathrm{E}}(\mathrm{x}=0,0.06,0.12,0.22$, $0.31,0.43$ wt. $\%$ ) was studied. The influence of rare earth elements on the corrosion resistance of Al-3.0 wt. $\% \mathrm{Mg}$ alloy under magnetic field was discussed.

\section{Experimental Procedure}

\subsection{Material preparation}

Pure aluminum ingot (99.7 wt.\%) was melted in a graphite crucible at $720{ }^{\circ} \mathrm{C}$ using an electrical resistance furnace. Pure magnesium (99.9 wt.\%) and R6535 mischmetal (37.3 wt.\%La, 61.5 wt.\%Ce) were pressed into the molten aluminum and held about 10 min to ensure they were completely dissolved. Then the degassing process was conducted with argon. Finally, the molten aluminum alloy was cast into test bar with dimensions of $14 \mathrm{~mm} \times 20$ $\mathrm{mm} \times 185 \mathrm{~mm}$ in a metal mould. As the burning loss of magnesium and mischmetal existed in the melting process, the actual compositions of the alloys were measured and listed in Table 1 . The $\mathrm{R}_{\mathrm{E}}(\mathrm{Ce}$ and La) content of the test bars was $0,0.06,0.12,0.22,0.31$ and $0.43 \mathrm{wt} . \%$, respectively. The presence of iron mainly came from the aluminum ingot. The test bars were cut into the specimens with the dimensions of $10 \mathrm{~mm} \times 10 \mathrm{~mm} \times 10 \mathrm{~mm}$ for immersion test and electrochemical measurement. The surface of the specimens was polished to mirror finish with $\mathrm{SiC}$ papers and diamond paste.

\subsection{Immersion test}

Two groups of the specimens were kept in $3.5 \mathrm{wt} . \% \mathrm{NaCl}$ solution. One of them was corroded under a $0.4 \mathrm{~T}$ horizontal magnetic field applied by Nd-Fe-B permanent-magnet. For a certain test time, the specimens were taken out and washed with fresh water and alcohol in the ultrasonic washing unit. Then they were dried with air blower and weighted by an electronic balance with an accuracy of $0.1 \mathrm{mg}$. The mass loss of each specimen was calculated. The duration of corrosion test lasted for 760 hours. The surface morphology of the specimens was observed under Hitach S-3400N scanning electron microscopy (SEM) and Olympus-BX51M optical microscopy (OM).

\subsection{Electrochemical measurement}

The corrosion process of the alloys was evaluated by electrochemical test with the help of PARSTAT 2273 electrochemical workstation. According to ASTM G1-03, the measurement was conducted in unsaturated 3.5 wt. $\%$ 
$\mathrm{NaCl}$ solution[21]. The test was carried out with three-electrode system. The specimen was used as the working electrode, the 232 model saturated calomel electrode as the reference electrode, and the 213 model Pt wire as the auxiliary electrode. A $0.4 \mathrm{~T}$ horizontal magnetic field was applied by Nd-Fe-B permanent-magnet as shown in Fig.1.

Potentiodynamic polarization test and electrochemical impendence spectroscopy (EIS) test were conducted according to ASTM G3-13[22]. The potentiodynamic polarization curves were recorded at a sweep rate of $1 \mathrm{mV} \cdot \mathrm{s}^{-1}$ after the open circuit potential (OCP) became steady. EIS test was done by applying sinusoidal potential excitation amplitude of $5 \mathrm{mV}$ at the OCP over the frequency range from $10^{5}$ to $10^{-2} \mathrm{~Hz}$. All measurements were repeated at least thrice to ensure the accuracy of the test results.

\section{Results and Discussion}

\subsection{Immersion test}

Fig.2 shows the mass loss of $\mathrm{Al}-3.0 \mathrm{wt} . \% \mathrm{Mg}-\mathrm{xR} \mathrm{R}_{\mathrm{E}}$ alloys in $\mathrm{NaCl}$ solution. $\mathrm{Al}-3.0 \mathrm{wt} \% \mathrm{Mg}-0.12 \mathrm{wt} . \% \mathrm{R}_{\mathrm{E}}$ alloy had the smallest mass loss as shown in Fig.2 (a). Meanwhile, The mass losses of the alloys with 0.06, 0.22 and 0.31 wt.\% $\mathrm{R}_{\mathrm{E}}$ content were also less than that of Al-3.0wt.\% Mg alloy without $\mathrm{R}_{\mathrm{E}}$ addition. But the alloy with highest $\mathrm{R}_{\mathrm{E}}$ content, up to 0.43 wt. $\%$, had the biggest mass loss.

When a $0.4 \mathrm{~T}$ magnetic field was applied, a similar result was obtained, as shown in Fig.2 (b). Under a $0.4 \mathrm{~T}$ magnetic field, Al-3.0 wt.\% Mg-0.12 wt.\% $\mathrm{R}_{\mathrm{E}}$ alloy had the smallest mass loss and Al-3.0 wt. $\% \mathrm{Mg}-0.43$ wt. $\% \mathrm{R}_{\mathrm{E}}$ alloy had the biggest mass loss. The alloys with 0.06 and $0.22 \mathrm{wt} . \% \mathrm{R}_{\mathrm{E}}$ content had less mass loss than the alloy without $\mathrm{R}_{\mathrm{E}}$ addition. The difference is that the mass loss of Al-3.0 wt.\%Mg- $0.31 \mathrm{wt} . \% \mathrm{R}_{\mathrm{E}}$ alloy was greater than Al-3.0 wt. $\% \mathrm{Mg}$ alloy under magnetic field, rather than smaller under no magnetic field. It seems that a $0.4 \mathrm{~T}$ magnetic field could decrease the corrosion resistance of Al-3.0 wt. $\% \mathrm{Mg}$ alloy with excessive $\mathrm{R}_{\mathrm{E}}$ content. The reason will be discussed late in this paper. All tested alloys had a lower mass loss under magnetic field than that under no magnetic field.

Fig. 3 shows the corroded surface of Al-3.0wt.\% Mg alloys after $760 \mathrm{~h}$ immersion test in $3.5 \mathrm{wt} . \% \mathrm{NaCl}$ solution. There were many pitting holes on the surface of tested samples. As we known, the number of pitting holes and its dimensions can be used to express the corrosion behavior of the alloys. In order to study the effect of magnetic field on the formation and growth of pitting holes, the number and diameter of pitting holes were investigated and the results were listed in Fig.4.

Comparing Fig. $3\left(a_{2}\right.$ to $\left.f_{2}\right)$ with Fig. $3\left(a_{1}\right.$ to $\left.f_{1}\right)$, it can be seen that Fig.3 $\left(a_{2}\right.$ to $\left.f_{2}\right)$ has less and smaller pitting holes when the $\mathrm{R}_{\mathrm{E}}$ content was less than 0.31 wt.\%. It seems that a $0.4 \mathrm{~T}$ horizontal magnetic field can impede the 
formation and the growth of pitting holes for Al-3.0wt.\%Mg-xR $R_{\mathrm{E}}$ alloy with no and low $\mathrm{R}_{\mathrm{E}}$ content. With the increase of $\mathrm{R}_{\mathrm{E}}$ content, the influence of magnetic field on the formation of pitting holes became small as shown in Fig.4 $\left(a_{1}\right.$ to $f_{1}$ ). But when $R_{E}$ content was up to $0.31 \mathrm{wt} . \%$ or more, the magnetic field would propagate the formation of the pitting holes. It reflected that the alloys corroded under a $0.4 \mathrm{~T}$ magnetic field had more pitting holes than the alloys corroded under no magnetic field application. So the effect of magnetic field on the formation of the pitting holes was different. It depends on $R_{E}$ content of the alloys in some extent. From Fig.4 $\left(a_{2}\right.$ to $\left.f_{2}\right)$, it can be seen that the diameter of the pitting holes formed under $0.4 \mathrm{~T}$ magnetic field is always smaller than that under no magnetic field applied. This result showed that $0.4 \mathrm{~T}$ magnetic field depressed the growth of the pitting holes.

The number and diameter of pitting holes of Al-3.0wt.\% Mg alloys with different content of $\mathrm{R}_{\mathrm{E}}$ are listed in Fig.5. When no magnetic field was applied, Al-3.0wt.\% Mg-0.12 wt.\% $\mathrm{R}_{\mathrm{E}}$ alloy had the least number and the smallest diameter of the pitting holes, as shown in Fig.5 (a) and (b). It meant that Al-3.0 wt.\%Mg-0.12 wt.\% $\mathrm{R}_{\mathrm{E}}$ alloy had the best corrosion resistance in 3.5 wt.\% NaCl solution. It was consistent with the test result shown in Fig.2 (a). At the same time, the number and diameter of the pitting holes of the alloys with $0.06,0.22$ and $0.31 \mathrm{wt} . \% \mathrm{R}_{\mathrm{E}}$ content were less and smaller than those of Al-3.0 wt.\% Mg alloy without $\mathrm{R}_{\mathrm{E}}$ addition, while the alloy with 0.43 wt. $\% \mathrm{R}_{\mathrm{E}}$ content had the most number and the biggest diameter of the pitting holes. When $0.4 \mathrm{~T}$ magnetic field was applied during the corrosion test, $\mathrm{Al}-3.0 \mathrm{wt} . \% \mathrm{Mg}-0.12 \mathrm{wt} . \% \mathrm{R}_{\mathrm{E}}$ alloy also had the least number and the smallest diameter of the pitting holes, while $\mathrm{Al}-3.0 \mathrm{wt} . \% \mathrm{Mg}-0.43 \mathrm{wt} . \% \mathrm{R}_{\mathrm{E}}$ alloy had the most number and the biggest diameter, as shown in Fig.5 (c) and (d). Al-3.0wt.\%Mg alloys with 0.06 and 0.22 wt.\% $\mathrm{R}_{\mathrm{E}}$ content had less number and smaller diameter than that without $\mathrm{R}_{\mathrm{E}}$ addition. Comparing the corrosion test results of different content of rare earth element under a $0.4 \mathrm{~T}$ horizontal magnetic field with no magnetic field, it can be found that the effect of magnetic field on the number and the dimension of the pitting holes are different. For example, Al-3.0 wt.\%Mg-0.31 wt.\% alloy had smaller diameter of pitting holes than Al-3.0 wt.\%Mg alloy under no magnetic field, but more number of pitting holes than $\mathrm{Al}-3.0 \mathrm{wt} . \% \mathrm{Mg}$ alloy under $0.4 \mathrm{~T}$ magnetic field.

Previous study[19] illustrated that the pitting corrosion took place at rich-iron phase. $\mathrm{Al}_{8} \mathrm{Mg}_{5}$ phase or at the $\mathrm{Al}_{4} \mathrm{Ce} / \mathrm{Al}_{4} \mathrm{La}$ phases area has different electrode potential from that of aluminum matrix[23]. Proper content of $\mathrm{R}_{\mathrm{E}}$ could decrease the amount of skeletal iron-rich phase, $\mathrm{Al}_{8} \mathrm{Mg}_{5}$ phase and oxide inclusions, while extra $\mathrm{R}_{\mathrm{E}}$ content would increase the number and size of acicular, skeletal and polygonal $\mathrm{Al}_{4} \mathrm{Ce} / \mathrm{Al}_{4} \mathrm{La}$ phases[19,24]. The number and the size of the second phases determine the number and the size of pitting holes greatly. The mass loss of the alloys was directly influenced by the number and the growth of the pitting holes. Consequently, the more and the bigger the second phases, the more and the larger the pitting holes, and the more serious the mass loss was. This 
rule is also effective when a $0.4 \mathrm{~T}$ magnetic field was applied. However, a magnetic field would influence the motion of cations and anions and have an effect on paramagnetic ion which is called "paramagnetic gradient force" and it will be discussed late.

\subsection{Electrochemical characteristics}

Fig.6 shows the potentiodynamic polarization curves of Al-3.0wt.\% Mg-xR $\mathrm{E}_{\mathrm{E}}$ alloys. A passive area with an unchanged current existed in anodic branch of polarization curve and there was no Tafel region in anodic polarization. So cathode extrapolation was used for Tafel curves and the corrosion current density $\left(\mathrm{i}_{\text {corr }}\right.$ ), corrosion potential $\left(\mathrm{E}_{\mathrm{corr}}\right)$, pitting corrosion potential $\left(\mathrm{E}_{\mathrm{pit}}\right)$ were calculated and listed in Table 2.

As shown in Fig.6, the horizontal magnetic field would decrease the $\mathrm{E}_{\text {corr }}$ values of the alloys. And with the increase of $\mathrm{R}_{\mathrm{E}}$ content, the difference of the $\mathrm{E}_{\mathrm{corr}}$ values $\left(E_{c o r r}^{0.4 T}-E_{\text {corr }}^{0 T}\right.$ ) of the same $\mathrm{R}_{\mathrm{E}}$ content alloys decreased from 0.054 $\mathrm{V}$ to $0.007 \mathrm{~V}$. The $\mathrm{i}_{\text {corr }}$ values of the alloy under magnetic field were lower than those of the alloys without magnetic field applied. It meant that magnetic field would slow down the corrosion rate of the alloys. However, the magnetic field has different effect on $\mathrm{E}_{\mathrm{pit}}$ values and depands on $\mathrm{R}_{\mathrm{E}}$ content of the alloys. But Al-3.0 wt.\%Mg-0.31\%wt. $\mathrm{R}_{\mathrm{E}}$ alloy and Al-3.0 wt.\%Mg-0.43\%wt. $\mathrm{R}_{\mathrm{E}}$ alloy had smaller $\mathrm{E}_{\mathrm{pit}}$ values after a $0.4 \mathrm{~T}$ magnetic field was applied. It seemed that $0.4 \mathrm{~T}$ magnetic field would increase the pitting corrosion sensibility of the alloy when the excessive $\mathrm{R}_{\mathrm{E}}$ was contented.

Pitting corrosion consists of at least two associated charge transfer reactions, the oxidation of metal (anodic reaction) and the reduction of an oxidizing agent (cathodic reaction). The effect of the magnetic field on the electrode process of $\mathrm{Al}-3.0 \mathrm{wt} . \% \mathrm{Mg}-\mathrm{xR}_{\mathrm{E}}$ alloys in $3.5 \mathrm{wt} . \% \mathrm{NaCl}$ solution could be recognized as the influence on the activating and dissolving of aluminum anode and mass transfer in solution and it is caused by the magnetohydrodynamic (MHD) flow on metal/solution interfaces due to the existance of a magnetic field. The MHD flow in electrochemical system is described by the force per unit volume in solution, $\vec{F}_{M H D}=\vec{J} \times \vec{B}$, where $\vec{J}$ is the local flux of ions.

The electronic field in the electrochemical system determines the directions of ions flux. So the direction of magnetic field plays a great role in the mass transfer rate. When the magnetic field is perpendicular to the direction of the ions flux, the electric field, $\vec{F}_{M H D}$ would be the largest. The magnetic field would produce an extra Lorentz force on charged particles moving through interfacial diffusion layer.

The dissolution of aluminum anodic could be considered as following reaction (1) and (2)[25,26]. At first, 
Aluminum is dissolved, losing electrons and forming active intermediate $\mathrm{Al}^{+}{ }_{\text {(ad) }}$ ions. The unstable $\mathrm{Al}^{+}{ }_{(\mathrm{ad})}$ ions loss electrons and become $\mathrm{Al}^{3+}$ ions. Then $\mathrm{Al}^{3+}$ ions and $\mathrm{Al}^{+}{ }_{(\text {ad) }}$ ions would react with $\mathrm{H}_{2} \mathrm{O}, \mathrm{O}_{2}$ and $\mathrm{Cl}^{-}$to dissolute the anodic and break the passive film. During the corrosion process of aluminum alloys, the movement of electrons and the recombination of ions are involved. The consumption of $\mathrm{Al}^{3+}$ is thought as the main cause to maintain progress of the pitting corrosion actively.

$$
\begin{gathered}
A l-e \rightarrow A l_{(a d)}^{+} \\
A l_{(a d)}^{+}-2 e \rightarrow A l^{3+}
\end{gathered}
$$

The magnetic field influences the motion of cations and anions and has an effect on paramagnetic ion which is called "paramagnetic gradient force" as shown in equation (3)[27-29]. Under a magnetic field, a concentration gradient of paramagnetic ions exist due to some electrode reaction in which they participate it will produce an additional driving force acting on them. This force has the same direction as the gradient of paramagnetic ions and causes a redistribution of paramagnetic ions in the diffusion layer and increases concentration of paramagnetic ions.

$$
\vec{F}_{\nabla c}=\frac{\chi_{m} B^{2}}{2 \mu_{0}} \vec{\nabla} c
$$

$\mathrm{Al}^{+}$(ad) ion forms first during the corrosion process of $\mathrm{Al}-3.0 \mathrm{wt} \% \mathrm{Mg}$ alloys in $3.5 \mathrm{wt} \% \mathrm{NaCl}$ solution and has the electron configuration of $1 \mathrm{~S}^{2} 2 \mathrm{~S}^{2} 2 \mathrm{P}^{6} 3 \mathrm{~S}^{1} 3 \mathrm{P}^{1}$. It has a single electron in orbit of $3 \mathrm{~S}$ and $3 \mathrm{P}$ each. $\mathrm{So}^{-\mathrm{Al}^{+}}$(ad) ion is a paramagnetic ion and can be attracted by the magnetic field and gather on the surface of aluminum electrode. The concentration of $\mathrm{Al}^{+}$(ad) ions is increased on the aluminum electrode surface. As a result of this, the progress of reaction (1) will be impeded and the formation of $\mathrm{Al}^{3+}$ ions will be reduced. So a magnetic field would decrease the concentration of ions in diffusion layer, and decrease the $\mathrm{i}_{\text {corr }}$ and increase the $\mathrm{E}_{\text {pit }}$ and $\mathrm{E}_{\text {corr }}$ of Al-3.0 wt.\%Mg alloys. When rare earth elements $\mathrm{Ce}$ and $\mathrm{La}$ were added into Al-3.0 wt.\% Mg alloys, $\mathrm{Ce}^{3+}$ and $\mathrm{La}^{3+}$ from the alloys would move faster towards the metal/solution interface and react more easily with oxygen than $\mathrm{Al}^{3+}$ ions would because $\mathrm{Ce}^{3+}-\mathrm{O}$ bond $\left(790 \mathrm{~kJ} \cdot \mathrm{mol}^{-1}\right)$ and $\mathrm{La}^{3+}-\mathrm{O}$ bond $\left(798 \mathrm{~kJ} \cdot \mathrm{mol}^{-1}\right)$ have higher binding energy than $\mathrm{Al}^{3+}-\mathrm{O}$ bond $(502$ $\left.\mathrm{kJ} \cdot \mathrm{mol}^{-1}\right)$ has. The paramagnetic gradient force would also accelerate the movement of $\mathrm{Ce}^{3+}$ and $\mathrm{La}^{3+}$ ions. When little content $R_{E}$ was added, rare earth elements were mainly used to eliminate the impurity and refine the grains and the alloy corroded under magnetic field had less number of pitting holes and higher $\mathrm{E}_{\mathrm{pit}}$ value than the alloys corroded under no magnetic field, as shown in Fig.4(b $\left.b_{1}\right),\left(c_{1}\right)$ and Fig.6 (b), (c). With the increase of $R_{E}$ content, extra $\mathrm{R}_{\mathrm{E}}$ would be induced to $\mathrm{Ce}^{3+}$ and $\mathrm{La}^{3+}$ ions by the magnetic field and increase the pitting corrosion sensibility. 
As the result, magnetic field would decrease $\mathrm{E}_{\mathrm{pit}}$ values and increase the pitting holes as shown in Fig.4( $\left.\mathrm{e}_{1}\right),\left(\mathrm{f}_{1}\right)$ and Fig.6(e), (f). More reactions happened among $\mathrm{Ce}^{3+}, \mathrm{La}^{3+}$ and $\mathrm{H}_{2} \mathrm{O}, \mathrm{O}_{2}, \mathrm{Cl}^{-}$under magnetic field would lead to more $\mathrm{Al}^{3+}$ and $\mathrm{Al}^{+}$(ad) ions gathering on the surface of aluminum electrode. It would inhibit the growth of pitting holes and decrease the corrosion rate, $\mathrm{E}_{\text {corr }}, \mathrm{i}_{\text {corr }}$, and the diameter of pitting holes as shown in Fig.4 $\left(\mathrm{a}_{2}\right.$ to $\left.\mathrm{f}_{2}\right)$ and Fig.6. Fig.7 shows the potentiodynamic polarization curves of Al-3.0wt.\%Mg-xR $\mathrm{E}_{\mathrm{E}}$ alloys. When no magnetic field was applied, with the increase of $\mathrm{R}_{\mathrm{E}}$ content, $\mathrm{E}_{\text {corr }}$ values and $\mathrm{E}_{\text {pit }}$ values shift to positive at first, and then shift toward negative direction as shown in Fig.7 (a) and Table 2. Al-3.0wt.\%Mg-0.12 wt.\%R $\mathrm{R}_{\mathrm{E}}$ alloy had the highest $\mathrm{E}_{\text {corr }}$ and $\mathrm{E}_{\mathrm{pit}}$ values. Al-3.0wt.\%Mg alloyed with $\mathrm{R}_{\mathrm{E}}$ had higher $\mathrm{E}_{\mathrm{pit}}$ values than the alloy without $\mathrm{R}_{\mathrm{E}}$ addition. Same exception happened to Al-3.0wt.\%Mg-0.43 wt.\% $\mathrm{R}_{\mathrm{E}}$ alloy that it had a lower $\mathrm{E}_{\text {corr }}$ value than Al-3.0wt.\%Mg alloy. With the increase of $\mathrm{R}_{\mathrm{E}}$ content, $\mathrm{i}_{\text {corr }}$ values decreased at the beginning, and then increased. Al-3.0wt.\%Mg-0.12 wt. $\% \mathrm{R}_{\mathrm{E}}$ alloy had the lowest $\mathrm{i}_{\text {corr }}$. The alloys contented 0.06 wt. $\%, 0.22$ wt. $\%$ and 0.31 wt. $\% \mathrm{R}_{\mathrm{E}}$ had lower $\mathrm{i}_{\text {corr }}$ values than Al-3.0wt.\%Mg alloy. When the $\mathrm{R}_{\mathrm{E}}$ content was up to $0.43 \mathrm{wt} . \%$, the $\mathrm{i}_{\text {corr }}$ values became the highest.

When the magnetic field was applied, the $\mathrm{E}_{\text {corr }}$ values increased first, then decreased with the increase of $\mathrm{R}_{\mathrm{E}}$ content, while the $\mathrm{i}_{\text {corr }}$ values decreased first, then increased, as shown in Fig.7 (b). Al-3.0wt.\%Mg-0.12 wt.\% $\mathrm{R}_{\mathrm{E}}$ had the highest $\mathrm{E}_{\text {corr }}$ value and lowest $\mathrm{i}_{\text {corr }}$. The alloys contented 0.06 and 0.22 wt. $\% \mathrm{R}_{\mathrm{E}}$ had higher $\mathrm{E}_{\text {corr }}$ and lower $\mathrm{i}_{\text {corr }}$ values than $\mathrm{Al}-3.0 \mathrm{wt} . \% \mathrm{Mg}$ alloy. When the $\mathrm{R}_{\mathrm{E}}$ content was up to $0.31 \mathrm{wt} . \%$ and more, the $\mathrm{E}_{\text {corr }}$ value became much low and $\mathrm{i}_{\text {corr }}$ value became much high. However, alloys contented $\mathrm{R}_{\mathrm{E}}$ had lower $\mathrm{E}_{\mathrm{pit}}$ values than Al-3.0wt.\% $\mathrm{Mg}$ alloy. So it can be concluded that the rare earth would increase the pitting corrosion sensibility of Al-3.0 wt.\% Mg $\mathrm{xR}_{\mathrm{E}}$ alloys under a magnetic field.

The effect on magnetic field on the Nyquist diagram of Al-3.0wt.\%Mg-xR $\mathrm{E}_{\mathrm{E}}$ alloys was clearly shown in Fig.8. It can be obviously seen that there were two capacitive impedance arcs. One is at high frequency (HF) and another at low frequency (LF). HF capacitive loop is attributed to the charge transfer reaction in the electric double layer formed at the corrosive medium closed to the metal specimens, which can be described by the charge transfer resistance $\left(R_{t}\right)$ and the oxide-layer capacitance of the original flat surface $\left(Q_{p}\right)[30]$. LF capacitive loop is generally related to the mass transport in solid phase and the diffusion of ions through the oxide films, or to the stable passive films on the surface, which can be assigned with $\mathrm{Q}_{\mathrm{dl}(\mathrm{pit})}$ and $\mathrm{R}_{\mathrm{t}(\mathrm{pit})}$. Thus, EIS of the tested alloys can be expressed by an equivalent circuit of Fig.9. The equivalent circuit parameters were calculated by ZSimpWin software and the results were listed in Table 3. It can be seen that the magnetic field increased the diameter of the capacitive circle of all the tested alloys. As we known that the diameter of the capacitive circle is associated with the charge transfer resistance. The bigger the diameter of the capacitive circle is, the slower the corrosion rate is. The $R_{t}$ means the 
activity of the alloys and the $R_{t(p i t)}$ means the resistance of ion diffusion through the passive films. The higher $R_{t}$ and $\mathrm{R}_{\mathrm{t}(\mathrm{pit})}$ values are, the lower activity and the more stable and compact passive films are. All alloys have small values of $R_{t}$ and $R_{t(p i t)}$ when they are tested under magnetic field, compared to under no magnetic field. It meant that under magnetic field the corrosion rate of $\mathrm{Al}-3.0 \mathrm{wt} . \%-\mathrm{x} \mathrm{R}_{\mathrm{E}}$ alloys would become slow.

Fig.10 shows the effect of rare earth content on the Nyquist diagram of Al-3.0wt.\%Mg alloys. When no magnetic field was applied, with the increase of $R_{E}$ content, the $R_{t}$ value increased at first, and then decreased. Al-3.0wt.\%Mg-0.12wt.\% $R_{E}$ alloy had the highest $R_{t}$ value. All of the alloys containing $R_{E}$ had the higher $R_{t}$ values than the alloy without $\mathrm{R}_{\mathrm{E}}$. It indicated that $\mathrm{R}_{\mathrm{E}}$ addition can reduce the activity of $\mathrm{Al}-3.0 \mathrm{wt} . \% \mathrm{Mg}$ alloys. Regard to the influence of rare earth on $R_{t(p i t)}$ values, $R_{E}$ could increase the $R_{t(p i t)}$ value when the $R_{E}$ content was from 0 to 0.12 wt.\%. Excessive $\mathrm{R}_{\mathrm{E}}$ content could decrease $\mathrm{R}_{\mathrm{t}(\mathrm{pit})}$ value. The $\mathrm{R}_{\mathrm{t}(\mathrm{pit})}$ value of Al-3.0wt.\% Mg-0.43 wt.\% $\mathrm{R}_{\mathrm{E}}$ alloy was even less than that of $\mathrm{Al}-3.0 \mathrm{wt} . \% \mathrm{Mg}$ alloy. This result reflected that there is a proper content of $\mathrm{R}_{\mathrm{E}}$ in Al-3.0wt.\% Mg-x $R_{E}$ alloy, and only in that case, $R_{E}$ addition was beneficial to enhancing the stability of the films and improve the corrosion resistance of the alloy.

In the magnetic field, the $R_{t}$ value increased with increase of $R_{E}$ content and it came to the largest when $R_{E}$ content was 0.12 wt. \%. However, the $\mathrm{R}_{\mathrm{t}(\mathrm{pit})}$ values became small due to the addition of $\mathrm{R}_{\mathrm{E}}$. So it meant that under this magnetic field, rare earth promoted the ion diffusion through the passive films and increased the pitting corrosion sensibility of Al-3.0wt.\%Mg alloys.

\section{Conclusions}

The effect of a $0.4 \mathrm{~T}$ horizontal magnetic field and rare earth element on the corrosion behavior of Al-3.0 wt. $\% \mathrm{Mg}$ alloy were investigated. The following conclusion was made.

(1) A horizontal magnetic field increased the corrosion potential $\left(\mathrm{E}_{\mathrm{corr}}\right)$, impeded the growth of pitting holes, and reduced the corrosion current density $\mathrm{i}_{\text {corr }}$ and pitting corrosion rate of $\mathrm{Al}-3.0 \mathrm{wt} . \% \mathrm{Mg}-\mathrm{xR} \mathrm{R}_{\mathrm{E}}(\mathrm{x}=0,0.06,0.12,0.22$, $0.31,0.43$ wt. \%) alloys.

(2) With the increase of $R_{E}$ content, the effect of magnetic field on $E_{\text {corr }}$ values of the alloys decreased. When $R_{E}$ content was less than $0.12 \%$, magnetic field had slight effect on the pitting corrosion potential $\left(\mathrm{E}_{\mathrm{pit}}\right)$. Excessive $\mathrm{R}_{\mathrm{E}}$ addition would enhance the effect of applied magnetic field on the pitting corrosion sensibility, decreasing the $\mathrm{E}_{\mathrm{pit}}$ values and increasing the number of pitting holes of the alloys.

(3) The corrosion rate was markedly reduced and corrosion resistance was effectively improved when a proper content of $\mathrm{R}_{\mathrm{E}}$ was added to Al-3.0 wt.\% Mg alloys. Excessive $\mathrm{R}_{\mathrm{E}}$ content would increase the pitting corrosion sensibility and resulted in the increase of corrosion rate due to the increase of the number and the size of second 
phases. Al-3.0 wt.\%Mg- $0.12 \mathrm{wt} . \% \mathrm{R}_{\mathrm{E}}$ alloy had best corrosion resistance among all of alloys.

\section{Acknowledgments}

This study was financially supported by the National Science Foundation of China (Nos. 51379070) and the Fundamental Research Funds for the Central Universities (2014B31714).

\section{Reference}

[1]Z.B. Xu, H. Hao, Electromagnetic interference shielding effectiveness of aluminum foams with different porosity, J. Alloy Compd. 617 (2014) 207-213.

[2] H.H. Chen, J.Y Wang, J. Lee, S. Lee, Superplasticity of AA5083 alloy as processed by equal channel angular extrusion, J. Alloy. Compd. 460 (2008) 305-308.

[3]Z.Y. Dou, G.H. Wu, X.L. Huang, D.L. Sun, L.T. Jian, Electromagnetic shielding effectiveness of aluminum alloy-fly ash composites, Compos. Part A-Appl. S. 38 (2007) 186-191.

[4]Y. Gao, L. Huang, Z.J. Zheng, H. Li, M. Zhu, The influence of cobalt on the corrosion resistance and electromagnetic shielding of electroless Ni-Co-P deposits on Al substrate, Appl. Surf. Sci. 253 (2007) 9470-9475.

[5]G. Wu, X. Huang, Z. Dou, S. Chen, L. Jiang, Electromagnetic interfering shielding of aluminum alloy-cenospheres composite, J. Mater. Sci. 42 (2007) 2633-2636.

[6]L. Guan, Y. Zhou, B. Zhang, J.Q. Wang, E.H. Han, W. Ke, Influence of aging treatment on the pitting behavior associated with the dissolution of active nanoscale $\beta$-phase precipitated for an Al-Mg alloy, Corro. Sci. 103 (2016) 255-267.

[7]J.A. Lyndon, R.K. Gupta, M.A. Gibson, N. Birbilis, Electrochemical behavior of the $\beta$-phase intermetallic (Mg2Al3) as a function of $\mathrm{PH}$ as relevant to corrosion of aluminum-magnesium alloys, Corro. Sci. 70 (2013) 290-293.

[8]Y. Wang, R.K. Gupta, N.L. Sukiman, R. Zhang, C.H.J. Davies, N. Birbilis, Influence of Alloyed Nd Content on the Corrosion of an Al-5 Mg Alloy. Corro. Sci. 73 (2013) 181-187.

[9]M. Bethencourt, F.J. Botana, J.J. Calvino, M. Marcos, M.A. Rodriguez-Chacón, Lanthanide compounds as environmentally-friendly corrosion inhibitors of aluminium alloys: a review, Corro. Sci. 40 (1998) 1803-1819. [10]S.M. Li, Y.G. Wang, J.H. Liu, W. Wei, Preparation of superhydrophobic coating on aluminum alloys with its anti-corrosion property, Acta. Phys-Chim. Sin. 23 (2007) 1631-1636.

[11]J.T. Zhang, C.Y. Yang, L. Pan, C.D. Li, Electrochemical study of corrosion resistance of cerium nitrate doped silane-based hybrid films on aluminum alloy 2A12, Acta. Phys-Chim. Sin. 44 (2008) 1372-1377.

[12]F. Rosalbino, S. Delsante, G. Borzone, E. Angelini, Influence of rare earth metals on the characteristics of anodic oxide films on aluminium and their dissolution behavior in $\mathrm{NaOH}$ solution, Corro. Sci. 52 (2010) 322-326.

[13]Y.H. Zhang, Z.R. Yin, Recrystallization of Al-Mg-Se-Zr alloys, Rare Metal Mat. Eng. 31 (2003) 167-170.

[14]Braun, Effectofthermal exposure onthe corrosion properties of an Al-Mg-Sc alloys sheet, Mater. Sci. Foru. 331 (2000) 9-14.

[15]S.J. Kim, S.K. Jang, Effects of solution heat treatment on corrosion resistance of 5083F Al alloy, T. Nonferr. Metal. Soc. 19 (2009) 887-891.

[16]S.J. Kim, S.K. Kim, J.C. Park, The corrosion and mechanical properties of Al alloy 5083-H116 in metal inert gas welding based on slow strain rate test, Surf. Coat. Tech. 205 (2010) 73-78.

[17]A. Zaki, U.H. Anwar, B.J. Abdul-Aleer, The corrosion behavior of scandium alloyed Al 5052 in neutral sodium chloride solution, Corro. Sci. 43 (2001) 1227-1243.

[18]F. Rosalbino, E. Angelini, N. De Negri, A. Saccone, S. Delfino, Influence of rare earth content on the electrochemical behaviour of Al-Mg-Er alloys, Intermetallics. 11 (2003) 435-441. 
[19]X. Zhang, Z.H. Z.H.Zhou, J.M. Xu, Effect of cerium and lanthanum on the corrosion behavior of Al-3.0wt.\%Mg alloy, J. Mater. Eng. Perform. 25 (2016) 1122-1128.

[20]X. Zhang, Z.H. Wang, Z.H.Zhou, J.M. Xu, Z.J. Zhong, H.L. Yuan, Corrosion behavior of Al-3.0wt.\%Mg alloy in $\mathrm{NaCl}$ solution under magnetic field, Rare Metals. 2016, doi:10.1007/s12598-016-0785-5.

[21]"Standard Practice for Preparing, Cleaning, and Evaluating Corrosion Test Specimens," G1-03, Annual Book of ASTM Standards, ASTM, 2003.

[22] Standard Practice for Conventions Applicable to Electrochemical Measurement in Corrosion Testing, G3-13, Annual Book of ASTM Standards, ASTM, 2013.

[23] Z.H. Huang, X.F. Guo, Z.M. Zhang and C.J. Xu, Effects of Ce on corrosion resistance of AZ91D magnesium alloy, Acta. Metall. Sin. 18 (2005) 129-136.

[24] X. Zhang, Z.H. Z.H.Zhou, J.M. Xu, Influence of rare earth (Ce and La) addition on the performance of Al-3.0 wt.\%Mg alloy, J. Wuhan Univ. Technol. 2016, Accept.

[25]Despić AR, Electrochemical properties of aluminum alloys containing indium, gallium and thallium. J. Appl. Electrochem. 6 (1976) 527-542.

[26]F.P. Ford, G.T. Burstein, T.P. Hoar, Bare surface reaction rates and their relation to environment controlled cracking of aluminum alloys. J. Electrochem. Soc. 127 (1980) 1325-1331.

[27]R.N. O'Brien, KSV. Santhanam, Electrochemical hydrodynamics in magnetic fields with laser interferometry: Influence of paramagnetic ions, J. Appl. Electrochem. 20 (1990) 427-437.

[28]G. Hinds, J.M.D. Coey, M.E.G. Lyons, Influence of magnetic forces on electrochemical mass transport, Electrochem. Commun. 3 (2001) 215-218.

[29]M. Waskaas, Y.I. Kharkats, Effect of magnetic fields on convection in solutions containing paramagnetic ions, J. Electronal Chem. 502 (2001) 51-57.

[30] Y.J. Shi, Q.L. Pan, M.J. Li, X. Huang, B. Li, Effect of Sc and Zr addition on corrosion behaviour of Al-Zn-Mg-Cu alloys, J Alloy. Comp. 612 (2014) 42-50. 


\section{Table Captions}

Table 1 The actual compositions of Al-3.0wt.\% Mg alloys (wt.\%).

Table $2 \mathrm{E}_{\text {corr }}, \mathrm{i}_{\text {corr }}, \mathrm{E}_{\text {pit }}$ valus of $\mathrm{Al}-3.0 \mathrm{wt} . \% \mathrm{Mg}-\mathrm{x} \mathrm{R}_{\mathrm{E}}$ alloys derived from the polarization curves.

Table 3 Parameters of the equivalent elements in equivalent circuit for different $\mathrm{R}_{\mathrm{E}}$ content alloys.

Table 1 The actual compositions of Al-3.0wt.\%Mg alloys (wt.\%).

\begin{tabular}{ccccccc}
\hline No. & 1 & 2 & 3 & 4 & 5 & 6 \\
\hline $\mathrm{Mg}$ & 2.97 & 2.98 & 3.03 & 3.06 & 3.02 & 2.98 \\
$\mathrm{Ce}$ & -- & 0.04 & 0.09 & 0.14 & 0.19 & 0.27 \\
$\mathrm{La}$ & -- & 0.02 & 0.03 & 0.08 & 0.12 & 0.16 \\
$\mathrm{Fe}$ & 0.14 & 0.11 & 0.08 & 0.10 & 0.08 & 0.09 \\
$\mathrm{Al}$ & Bal. & Bal. & Bal. & Bal. & Bal. & Bal. \\
\hline
\end{tabular}

Table $2 \mathrm{E}_{\text {corr }}, \mathrm{i}_{\text {corr }}, \mathrm{E}_{\text {pit }}$ valus of Al-3.0wt.\%Mg-xR $\mathrm{E}_{\mathrm{E}}$ alloys derived from the polarization curves.

\begin{tabular}{|c|c|c|c|c|c|c|c|c|c|}
\hline \multirow{2}{*}{$\mathrm{R}_{\mathrm{E}}(\mathrm{wt} . \%)$} & \multicolumn{2}{|c|}{$\mathrm{E}_{\text {corr }} / \mathrm{V}$} & \multirow{2}{*}{$\begin{array}{c}\triangle \mathrm{E}_{\text {corr }} \\
/ \mathrm{V}\end{array}$} & \multicolumn{2}{|c|}{$\mathrm{i}_{\text {corr }} / \mu \mathrm{A} \cdot \mathrm{cm}^{-2}$} & \multirow{2}{*}{$\begin{array}{c}\triangle \mathrm{i}_{\text {corr }} \\
/ \mu \mathrm{A} \cdot \mathrm{cm}^{-2}\end{array}$} & \multicolumn{2}{|c|}{$\mathrm{E}_{\mathrm{pit}} / \mathrm{V}$} & \multirow{2}{*}{$\begin{array}{c}\triangle \mathrm{E}_{\mathrm{pit}} \\
/ \mathrm{V}\end{array}$} \\
\hline & $0 \mathrm{~T}$ & $0.4 \mathrm{~T}$ & & $0 \mathrm{~T}$ & $0.4 \mathrm{~T}$ & & $0 \mathrm{~T}$ & $0.4 \mathrm{~T}$ & \\
\hline 0 & -1.218 & -1.164 & 0.054 & 7.572 & 5.225 & -2.347 & -0.924 & -0.872 & 0.052 \\
\hline 0.06 & -1.212 & -1.158 & 0.054 & 5.027 & 3.321 & -1.706 & -0.899 & -0.895 & 0.004 \\
\hline 0.12 & -1.164 & -1.137 & 0.027 & 5.003 & 2.980 & -2.023 & -0.855 & -0.852 & 0.003 \\
\hline 0.22 & -1.198 & -1.177 & 0.021 & 5.602 & 3.819 & -1.783 & -0.903 & -0.891 & 0.012 \\
\hline 0.31 & -1.225 & -1.214 & 0.011 & 5.766 & 4.049 & -1.717 & -0.905 & -0.936 & -0.031 \\
\hline 0.43 & -1.265 & -1.258 & 0.007 & 10.475 & 7.446 & -3.029 & -0.919 & -0.961 & -0.042 \\
\hline
\end{tabular}

Table 3 Parameters of the equivalent elements in equivalent circuit for different $R_{E}$ content alloys.

\begin{tabular}{ccccccccc}
\hline $\begin{array}{c}\mathrm{R}_{\mathrm{E}} \\
(\text { wt.\% })\end{array}$ & $\begin{array}{c}\text { Magnetic } \\
\text { intensity(T) }\end{array}$ & $\begin{array}{c}\mathrm{R}_{\text {sol }} \\
\left(\Omega \cdot \mathrm{cm}^{2}\right)\end{array}$ & $\begin{array}{c}\mathrm{Q}_{\mathrm{p}} \\
\left(\Omega^{-1} \cdot \mathrm{cm}^{-2} \cdot \mathrm{s}^{-1}\right)\end{array}$ & $\begin{array}{c}\mathrm{n} 1 \\
\mathrm{R}_{\mathrm{t}}\end{array}$ & $\begin{array}{c}\mathrm{Q}_{\mathrm{dl}} \\
\left(\Omega \cdot \mathrm{cm}^{2}\right)\end{array}$ & $\begin{array}{c}\mathrm{n} 2 \\
\left(\Omega^{-1} \cdot \mathrm{cm}^{-2} \cdot \mathrm{s}^{-1}\right)\end{array}$ & $\begin{array}{c}\mathrm{R}_{\mathrm{t}(\mathrm{pit})} \\
\left(\Omega \cdot \mathrm{cm}^{2}\right)\end{array}$ \\
\hline 0 & 0 & 9.53 & $9.02 \times 10^{-6}$ & 0.8771 & $1.78 \times 10^{4}$ & $10.04 \times 10^{-6}$ & 0.9432 & $1.28 \times 10^{4}$ \\
& 0.4 & 8.15 & $7.32 \times 10^{-6}$ & 0.8881 & $3.94 \times 10^{4}$ & $14.72 \times 10^{-6}$ & 0.8776 & $6.94 \times 10^{4}$ \\
0.06 & 0 & 8.85 & $8.25 \times 10^{-6}$ & 0.8907 & $2.94 \times 10^{4}$ & $6.16 \times 10^{-6}$ & 0.8829 & $1.71 \times 10^{4}$ \\
& 0.4 & 8.25 & $5.37 \times 10^{-6}$ & 0.9113 & $5.34 \times 10^{4}$ & $10.48 \times 10^{-6}$ & 0.8685 & $4.49 \times 10^{4}$ \\
0.12 & 0 & 19.34 & $11.71 \times 10^{-6}$ & 0.8423 & $7.71 \times 10^{4}$ & $3.91 \times 10^{-6}$ & 0.9813 & $1.94 \times 10^{4}$ \\
& 0.4 & 20.48 & $6.46 \times 10^{-6}$ & 0.8740 & $6.61 \times 10^{4}$ & $9.53 \times 10^{-6}$ & 0.8456 & $5.22 \times 10^{4}$ \\
0.22 & 0 & 9.42 & $5.91 \times 10^{-6}$ & 0.9378 & $6.83 \times 10^{4}$ & $8.94 \times 10^{-6}$ & 0.8829 & $1.62 \times 10^{4}$ \\
& 0.4 & 8.39 & $1.70 \times 10^{-6}$ & 0.8977 & $7.25 \times 10^{4}$ & $9.22 \times 10^{-6}$ & 0.8084 & $4.31 \times 10^{4}$ \\
0.31 & 0 & 10.28 & $11.43 \times 10^{-6}$ & 0.8582 & $3.70 \times 10^{4}$ & $8.41 \times 10^{-6}$ & 0.8361 & $1.06 \times 10^{4}$ \\
& 0.4 & 7.95 & $5.96 \times 10^{-6}$ & 0.9168 & $5.45 \times 10^{4}$ & $5.03 \times 10^{-6}$ & 0.7985 & $4.17 \times 10^{4}$ \\
0.43 & 0 & 9.89 & $9.36 \times 10^{-6}$ & 0.8657 & $3.63 \times 10^{4}$ & $7.73 \times 10^{-6}$ & 0.8139 & $0.91 \times 10^{4}$ \\
& 0.4 & 7.85 & $7.40 \times 10^{-6}$ & 0.8858 & $4.03 \times 10^{4}$ & $3.71 \times 10^{-6}$ & 0.9855 & $3.61 \times 10^{4}$ \\
\hline
\end{tabular}




\section{Figure Captions}

Fig.1 Placement of the electrodes and a magnetic field.

Fig.2 Mass loss of Al-3.0wt.\%Mg alloys in 3.5 wt.\% NaCl solution: (a) No magnetic field; (b) 0.4T horizontal magnetic field.

Fig.3 The surface morphology of Al-3.0wt.\% Mg alloys in 3.5 wt. \% NaCl solution.

Fig. 4 Effect of magnetic field on pitting holes of Al-3.0wt.\%Mg-X\% $\mathrm{R}_{\mathrm{E}}$ alloys corroded in $3.5 \mathrm{wt} . \% \mathrm{NaCl}$ solution: (a) 0 wt. \%; (b) 0.06 wt.\%; (c) 0.12 wt.\%; (d) 0.22 wt.\%; (e) 0.31 wt.\%; (f) 0.43 wt.\%.

Fig.5 Effect of rare earth content on the number and diameter of pitting holes of Al-3.0wt.\% $\mathrm{Mg}-\mathrm{x} \% \mathrm{R} \mathrm{E}_{\mathrm{E}}$ alloys: number (a) and diameter (b) of pitting holes, no magnetic field; number (c) and diameter (d) of pitting holes; with a $0.4 \mathrm{~T}$ horizontal magnetic field.

Fig.6 Potentiodynamic polarization curves of Al-3.0wt.\% $\mathrm{Mg}-\mathrm{xR}_{\mathrm{E}}$ alloys in $3.5 \mathrm{wt} . \% \mathrm{NaCl}$ solution: (a) 0 wt.\%; (b) 0.06 wt.\%; (c) 0.12 wt.\%; (d) 0.22 wt.\%; (e) 0.31 wt.\%; (f) 0.43 wt.\%.

Fig.7 Effect of rare earth on potentiodynamic polarization curves of Al-3.0wt.\% Mg-xR $\mathrm{E}_{\mathrm{E}}$ alloys in $3.5 \mathrm{wt} . \% \mathrm{NaCl}$ solution: (a) no magnetic field; (b) with a $0.4 \mathrm{~T}$ horizontal magnetic field.

Fig.8 Nyquist diagram of Al-3.0wt. $\% \mathrm{Mg}-\mathrm{xR}_{\mathrm{E}}$ alloy: (a) $\mathrm{x}=0$ wt.\%; (b) x=0.1 wt.\%; (c) x=0.2 wt.\%; (d) x=0.3 wt.\%; (e) $\mathrm{x}=0.4$ wt. $\%$; (f) $\mathrm{x}=0.5$ wt. $\%$.

Fig.9 An equivalent circuit for the tested alloys.

Fig.10 Effect of rare earth content on impendence spectroscopy of Al-3.0wt.\% Mg alloys in 3.5wt.\% $\mathrm{NaCl}$ solution: (a) without magnetic field; (b) with a $0.4 \mathrm{~T}$ horizontal magnetic field.

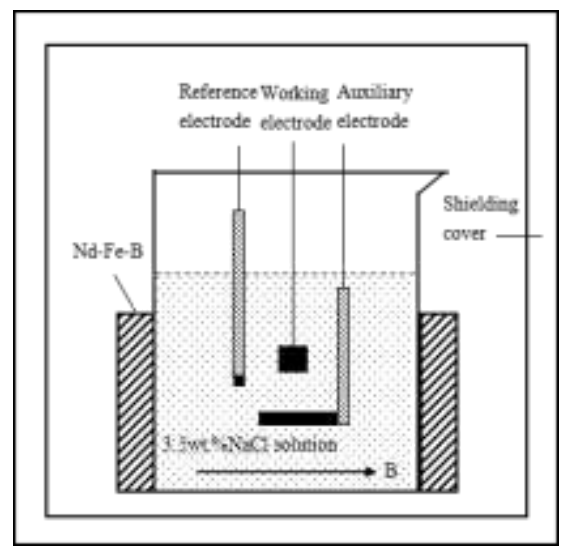

Fig.1 Placement of the electrodes and a magnetic field.
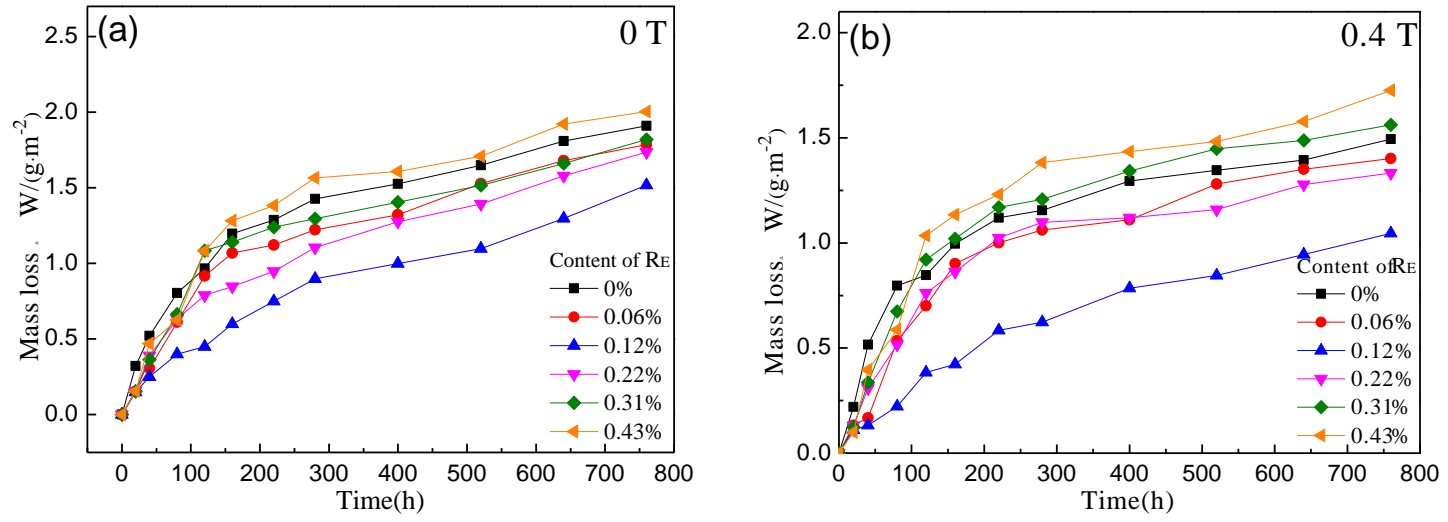

Fig.2 Mass loss of Al-3.0wt.\%Mg alloys in $3.5 \mathrm{wt} . \% \mathrm{NaCl}$ solution: (a) No magnetic field; (b) 0.4T horizontal magnetic field. 


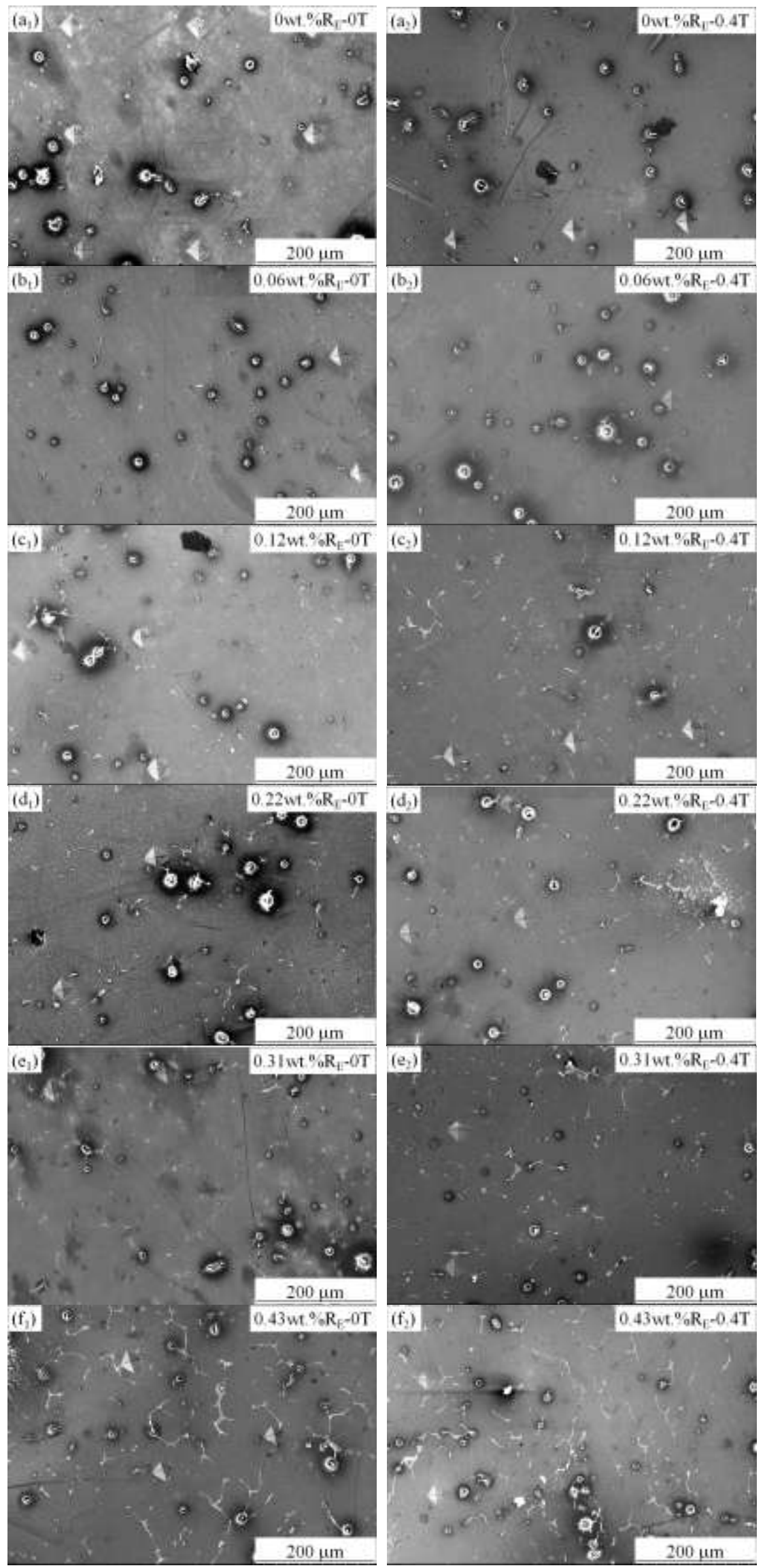

Fig.3 The surface morphology of Al-3.0wt.\%Mg alloys in 3.5 wt. $\% \mathrm{NaCl}$ solution. 

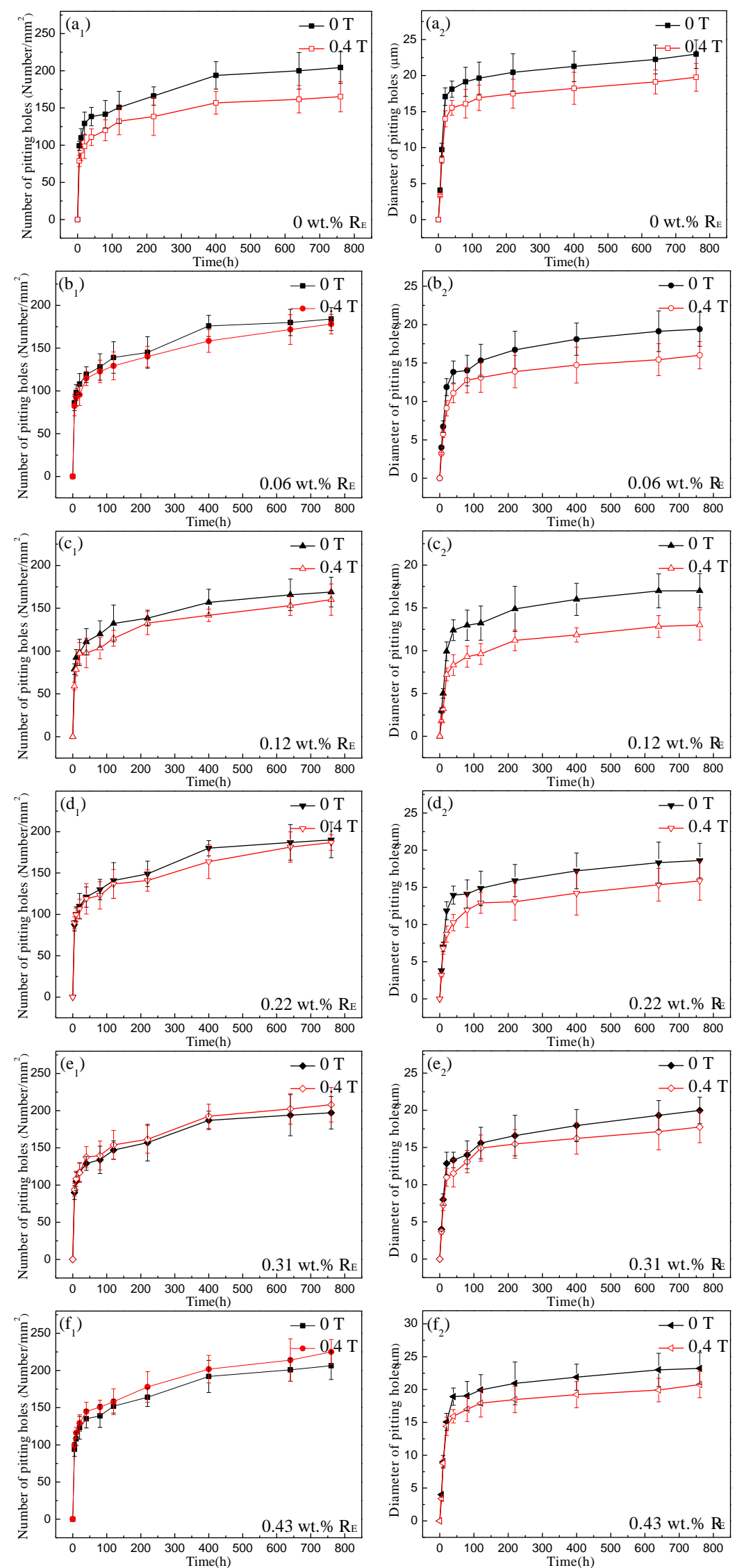

Fig. 4 Effect of magnetic field on pitting holes of Al-3.0wt.\%Mg-x\% $\mathrm{R}_{\mathrm{E}}$ alloys corroded in $3.5 \mathrm{wt} . \% \mathrm{NaCl}$ solution: (a) 0 wt.\%; (b) 0.06 wt.\%; (c) 0.12 wt.\%; (d) 0.22 wt.\%; (e) 0.31 wt.\%; (f) 0.43 wt.\%. 

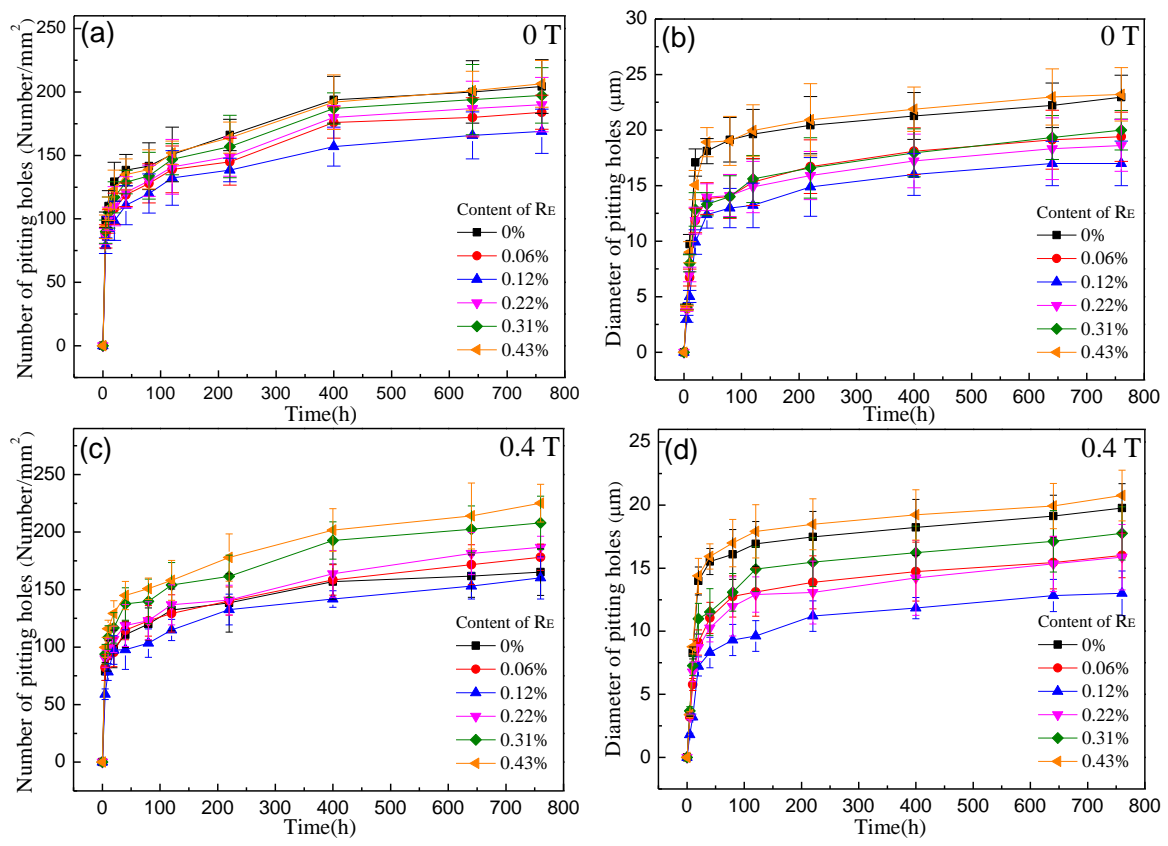

Fig.5 Effect of rare earth content on the number and diameter of pitting holes of Al-3.0wt. $\% \mathrm{Mg}-\mathrm{x} \% \mathrm{R}_{\mathrm{E}}$ alloys: number (a) and diameter (b) of pitting holes, no magnetic field; number (c) and diameter (d) of pitting holes; with a 0.4 T horizontal magnetic field.
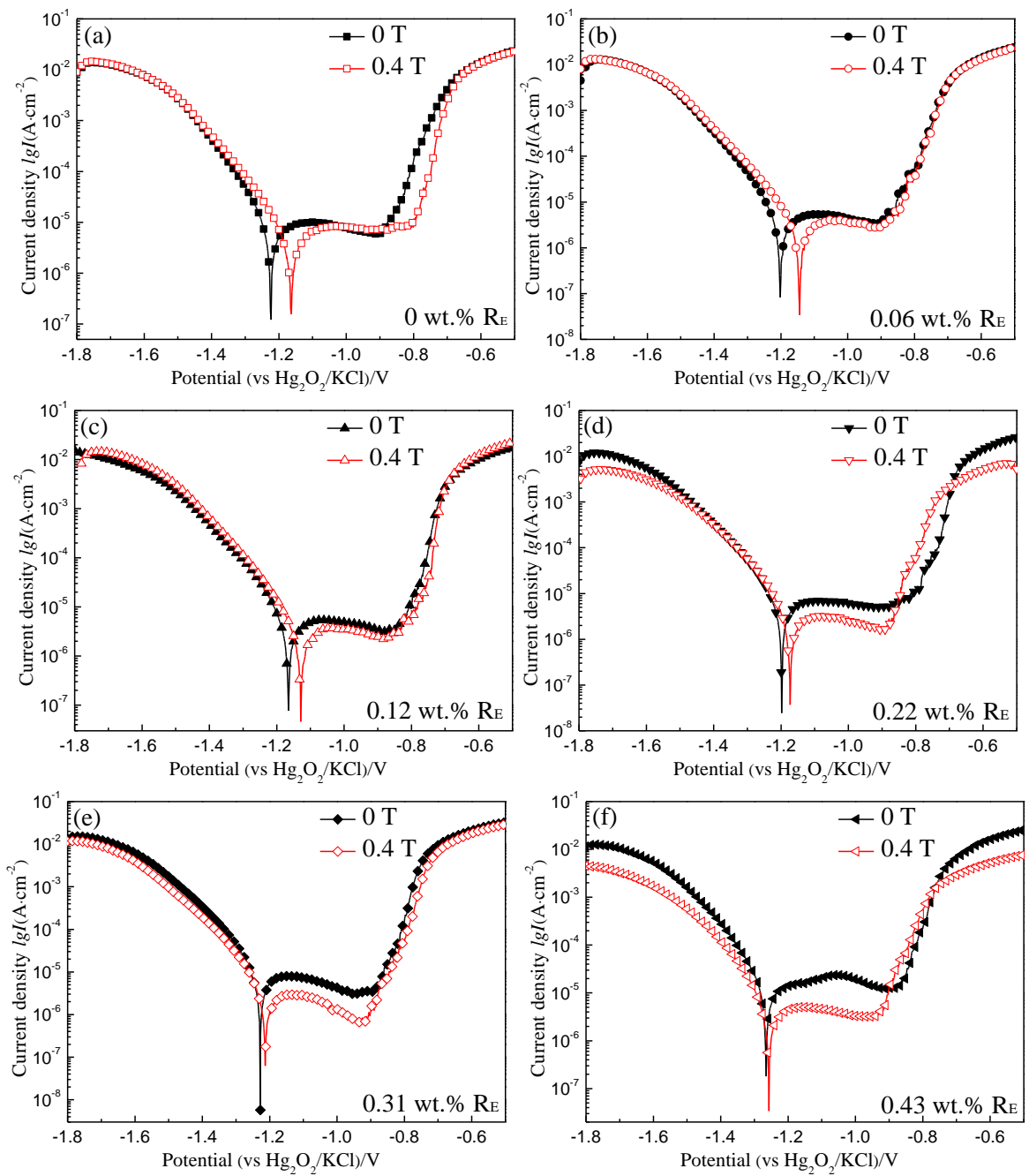

Fig.6 Potentiodynamic polarization curves of Al-3.0wt.\% $\mathrm{Mg}-\mathrm{xR}_{\mathrm{E}}$ alloys in $3.5 \mathrm{wt} \% \mathrm{NaCl}$ solution: (a) 0 wt.\%; (b) 0.06 wt.\%; (c) 0.12 wt. $\%$; (d) 0.22 wt.\%; (e) 0.31 wt.\%; (f) 0.43 wt.\%. 

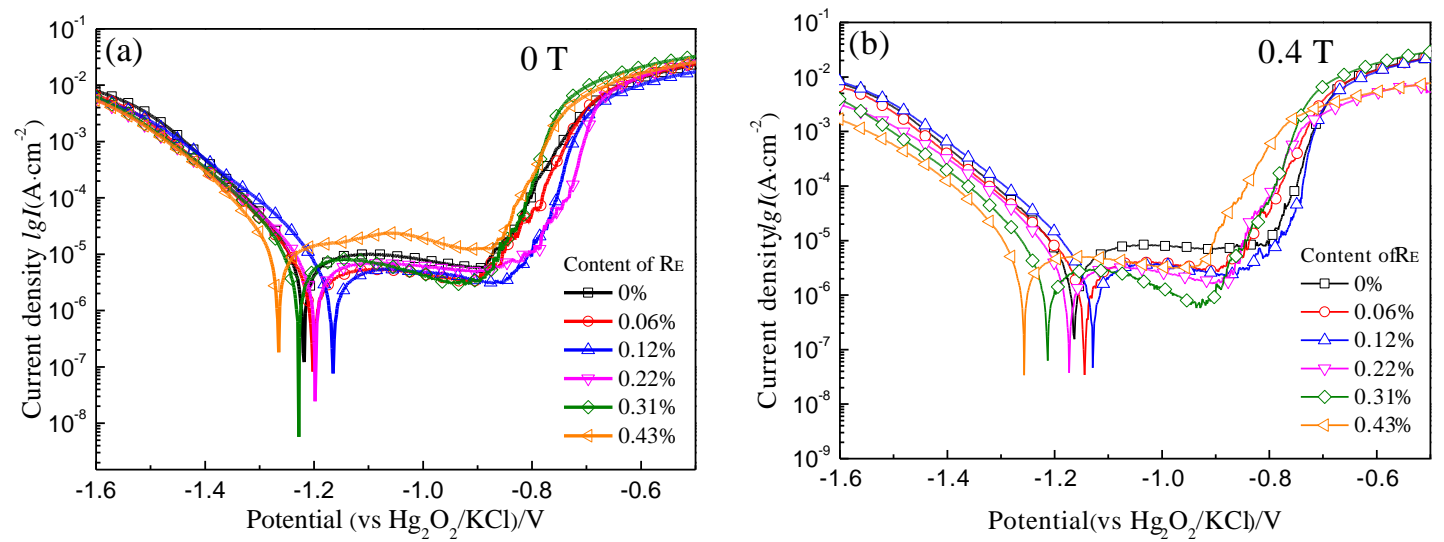

Fig.7 Effect of rare earth on potentiodynamic polarization curves of $\mathrm{Al}-3.0 \mathrm{wt} . \% \mathrm{Mg}-\mathrm{xR}_{\mathrm{E}}$ alloys in $3.5 \mathrm{wt} . \% \mathrm{NaCl}$ solution: (a) no magnetic field; (b) with a $0.4 \mathrm{~T}$ horizontal magnetic field.
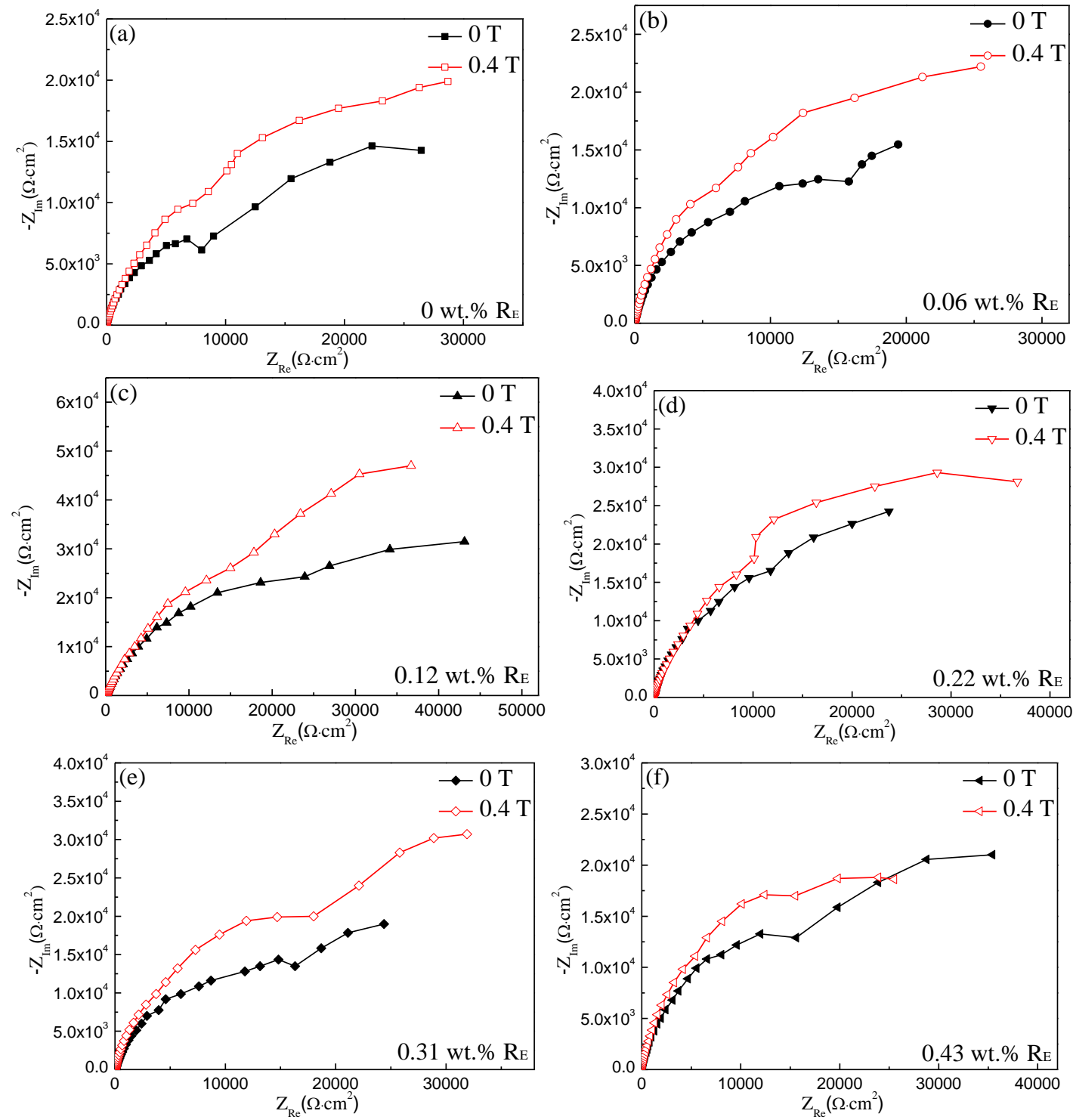

Fig.8 Nyquist diagram of Al-3.0wt. $\% \mathrm{Mg}-\mathrm{xR}$ E alloy: (a) $\mathrm{x}=0$ wt. \%; (b) $\mathrm{x}=0.1$ wt. \%; (c) $\mathrm{x}=0.2$ wt. \%; (d) $\mathrm{x}=0.3$ wt. \%; (e) $\mathrm{x}=0.4$ wt. \%; (f) $\mathrm{x}=0.5$ wt. $\%$. 


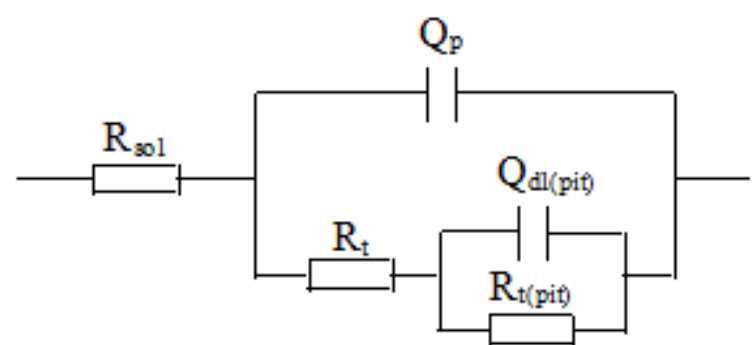

Fig.9 An equivalent circuit for the tested alloys
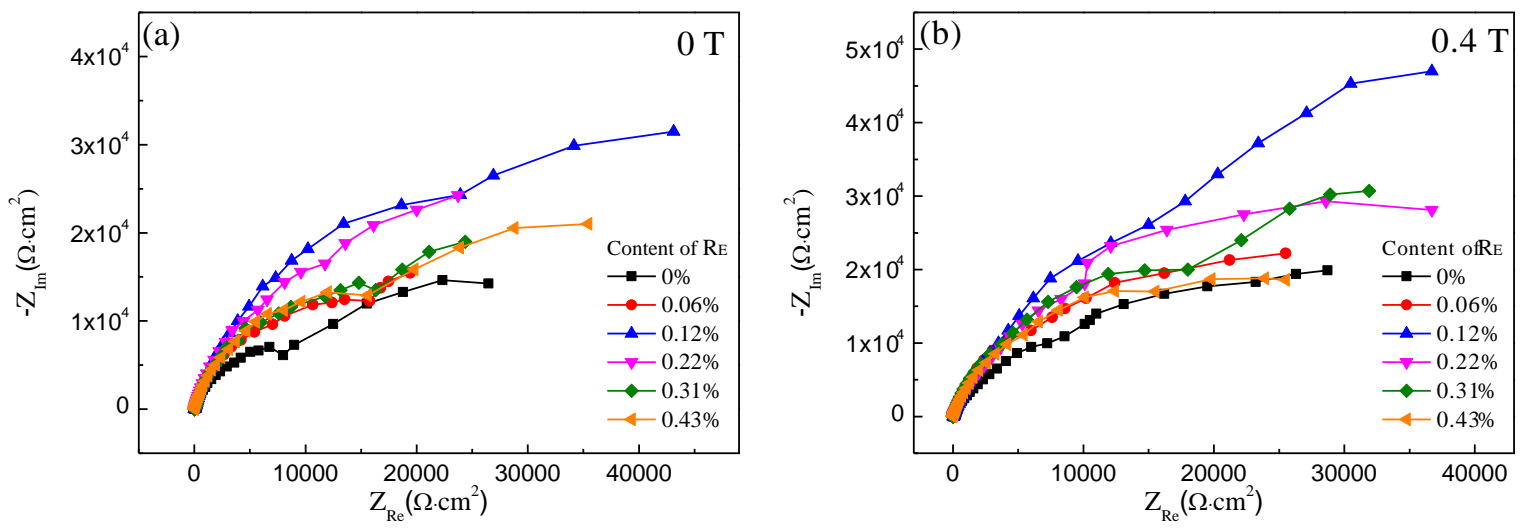

Fig.10 Effect of rare earth content on impendence spectroscopy of $\mathrm{Al}-3.0 \mathrm{wt} . \% \mathrm{Mg}$ alloys in $3.5 \mathrm{wt} . \% \mathrm{NaCl}$ solution: (a) without magnetic field; (b) with a $0.4 \mathrm{~T}$ horizontal magnetic field. 